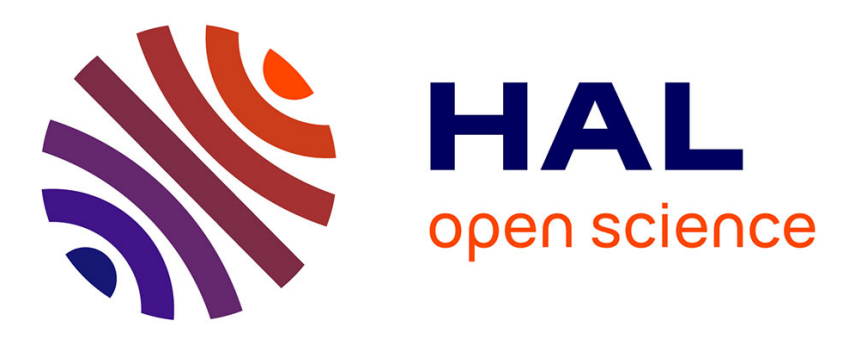

\title{
Existence of a bicontinuous zone in microemulsion systems
}

\author{
F. Larche, J. Rouvière, P. Delord, B. Brun, J.L. Dussossoy
}

\section{To cite this version:}

F. Larche, J. Rouvière, P. Delord, B. Brun, J.L. Dussossoy. Existence of a bicontinuous zone in microemulsion systems. Journal de Physique Lettres, 1980, 41 (18), pp.437-440. 10.1051/jphyslet:019800041018043700 . jpa-00231816

\section{HAL Id: jpa-00231816 https://hal.science/jpa-00231816}

Submitted on 1 Jan 1980

HAL is a multi-disciplinary open access archive for the deposit and dissemination of scientific research documents, whether they are published or not. The documents may come from teaching and research institutions in France or abroad, or from public or private research centers.
L'archive ouverte pluridisciplinaire HAL, est destinée au dépôt et à la diffusion de documents scientifiques de niveau recherche, publiés ou non, émanant des établissements d'enseignement et de recherche français ou étrangers, des laboratoires publics ou privés. 


\title{
Existence of a bicontinuous zone in microemulsion systems $\left({ }^{*}\right)$
}

\author{
F. Larche, J. Rouvière, P. Delord, B. Brun and J. L. Dussossoy \\ Groupe de Dynamique des Phases Condensées (**), U.S.T.L., 34060 Montpellier Cedex, France
}

(Reçu le 9 avril 1980, accepté le 21 juillet 1980)

\begin{abstract}
Résumé. - L'interprétation conjointe d'expériences d'auto-diffusion et de conductivité montre qu'il existe, dans le domaine isotrope des microémulsions, une zone à caractère continu aussi bien pour la partie huileuse que la partie aqueuse. Sa délimitation est liée de manière importante, mais non unique, à la fraction volumique d'eau du système.
\end{abstract}

\begin{abstract}
The interpretation of self-diffusion and conductivity studies shows the existence of a zone within the isotropic microemulsion domain, where the aqueous and oily phase are both continuous. The boundary of this zone is strongly but not uniquely related to the water volume fraction of the system.
\end{abstract}

1. Introduction. - The microstructure of the isotropic phase (usually called microemulsion) in complex surfactant systems (hydrocarbon-water-surfactant-alcohol) has been mainly studied in the regions rich in water or rich in oil [1, 2]. Light spectroscopy $[3,4]$ and small angle $X$-ray or neutron scattering $[5,6,7]$ are usually interpreted in terms of droplets dispersed in a continuous medium. As the ratio oil/water is increased, some systems go from a direct $(\mathrm{O} / \mathrm{W})$ structure through a liquid crystalline phase to an inverted $(\mathrm{W} / \mathrm{O})$ structure $[8,9]$. Some other systems present a continuous isotropic zone $[10,11]$. The structure of the concentrated middle zone is still speculative. Selfdiffusion and conductivity studies have been undertaken to gain insight into this region of the diagram.

2. Experimental methods and results. - The system chosen is decane/water/sodium p-octylbenzene sulfonate (OBS)/1-pentanol/sodium chloride. This last component was maintained at $0.3 \mathrm{wt} . \%$ with respect to water, so as to give a large homogeneous zone in the diagram. The studies reported here pertain to a constant ratio of the alcohol (CTA) to the surfactant (TA) of 2.1 by weight. The origin or methods of preparation of the products have been already detailed [12].

The open-ended capillary tube method using radioactive labelling was used for self-diffusion and has been described in reference [12]. The labelled atoms

$\left({ }^{*}\right)$ Work supported by contract D.G.R.S.T. 78-7-2199 RAP. (**) L.A. 233. were ${ }^{22} \mathrm{Na},{ }^{36} \mathrm{Cl},{ }^{35} \mathrm{~S},{ }^{3} \mathrm{H}$ and ${ }^{14} \mathrm{C}$. Data were taken at $25 \pm 0.1{ }^{\circ} \mathrm{C}$. Conductivity was measured at the same temperature at $4.0 \mathrm{kHz}$ with a Leeds and Northrup admittance bridge.

Measurements of the diffusion coefficients of the surfactant $D_{\mathrm{S}}$, the decane $D_{\mathrm{D}}$, the water $D_{\mathrm{w}}$, the sodium $D_{\mathrm{Na}}$ and the chlorine $D_{\mathrm{Cl}}$ as well as the conductivities were taken along the lines represented (Fig. 1) on a pseudo-ternary diagram. The results are plotted

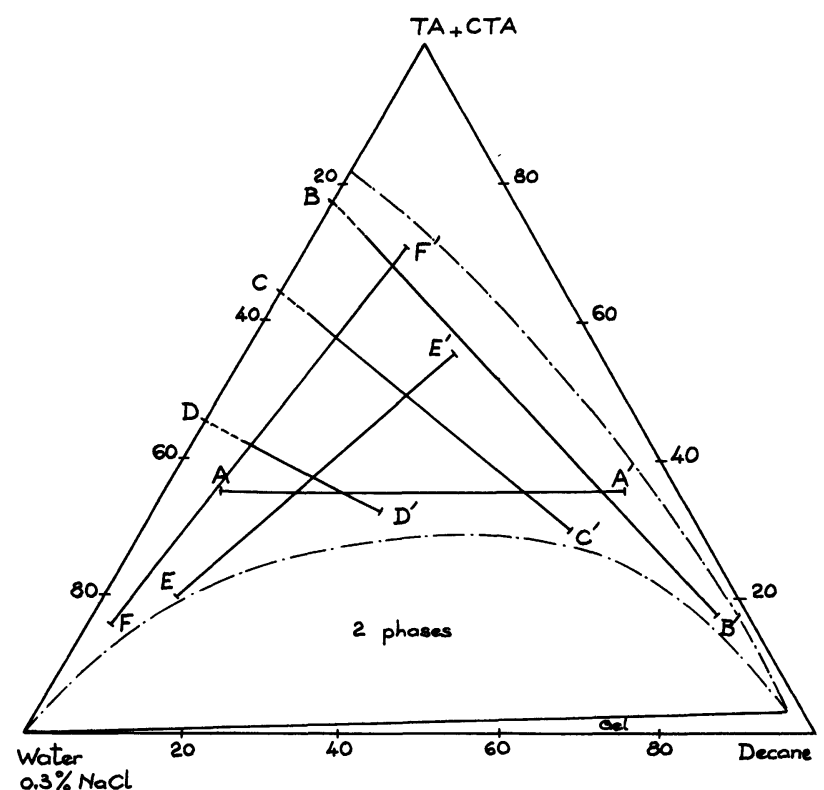

Fig. 1. - The isotropic homogeneous zone of the pseudoternary diagram decane/water +0.3 wt. $\%$. NaCl/1-pentanol/sodium poctylbenzene sulfonate at $\mathrm{CTA} / \mathrm{TA}=2.1$ by weight. Investigations were made along $\mathrm{AA}^{\prime}, \mathrm{BB}^{\prime}, \mathrm{CC}^{\prime}, \mathrm{DD}^{\prime}, \mathrm{EE}^{\prime}$ and $\mathrm{FF}^{\prime}$. 


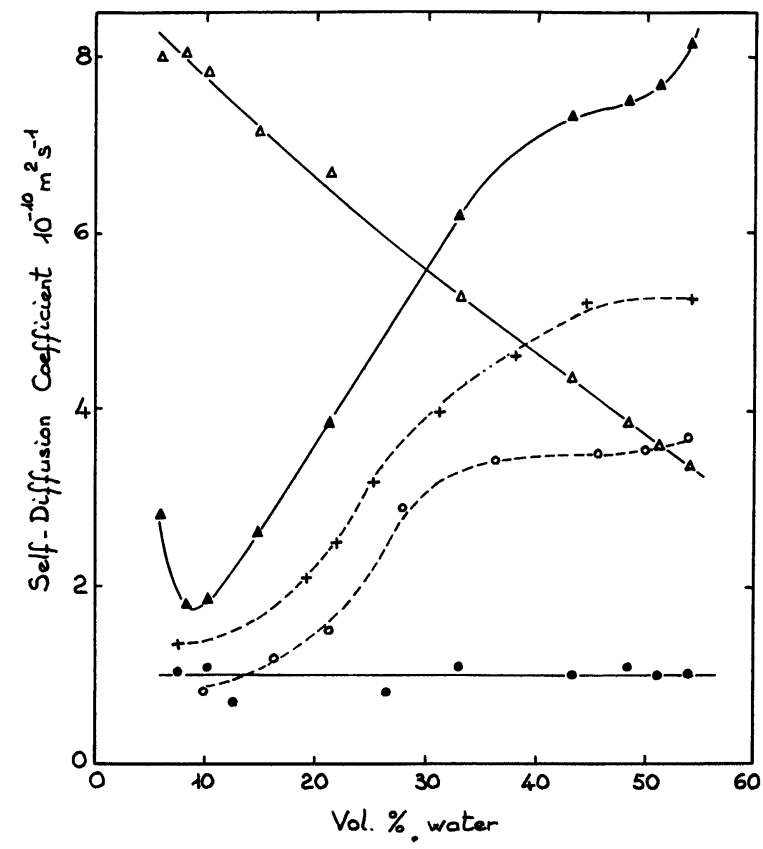

Fig. 2. - Self-diffusion coefficients along $\mathrm{AA}^{\prime}$ as a function of the volume fraction of water. Decane- $\triangle-$; water- $\Delta-$; sodium-O-; chlorine-+-; OBS •.

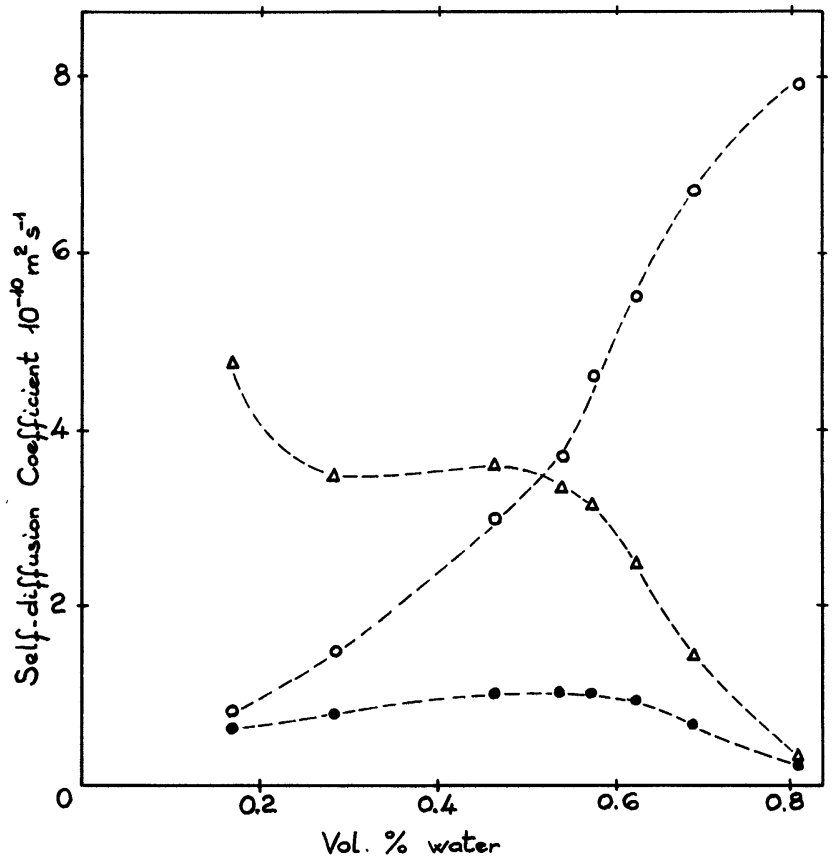

Fig. 3. - Self-diffusion coefficients along $\mathrm{FF}^{\prime}$ as a function of the volume fraction of water. Same symbols as in figure 2 .

on figures 2 to 7 as a function of the volume fraction of water $\Phi$. This last quantity was computed taking as densities $\left(10^{-3} \mathrm{~kg} \cdot \mathrm{m}^{-3}\right): 1.001$ for water plus sodium chloride, 0.73 for decane, 0.8144 for pentanol [13], 1.11 for OBS [6] and assuming additivity of the volumes. Measurements of the density of the solution [11] and calculation of $\Phi$ assuming that only $\mathrm{NaCl}$ is dissolved in water yields a value differing only by 2 to $3 \%$.

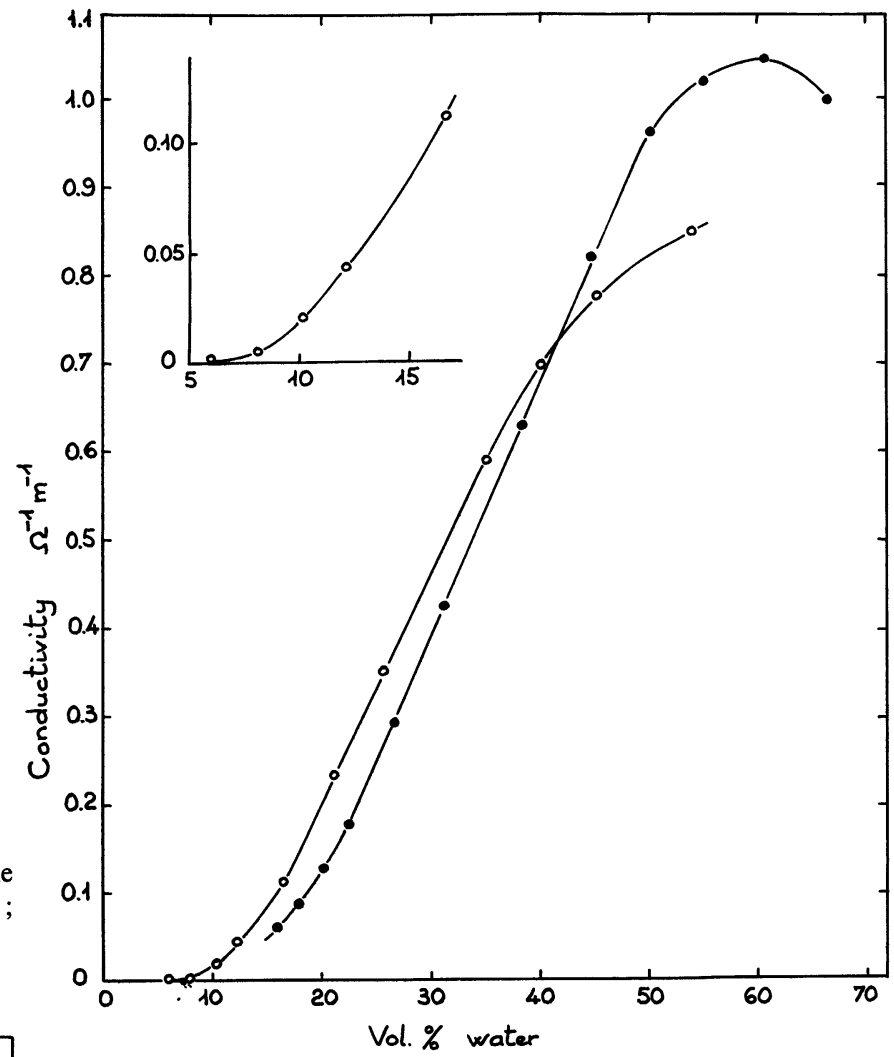

Fig. 4. - Conductivity along $\mathrm{AA}^{\prime}(0)$ and $\mathrm{EE}^{\prime}(\bullet)$ as a function of the volume fraction of water. In the left upper corner, expended low water content part of $\mathrm{AA}^{\prime}$. The curves intersect at $\Phi$ slightly different that $\mathrm{EE}^{\prime}$ and $\mathrm{AA}^{\prime}$ on figure 1 . This is probably due to uncertainty on the composition of the base solutions.

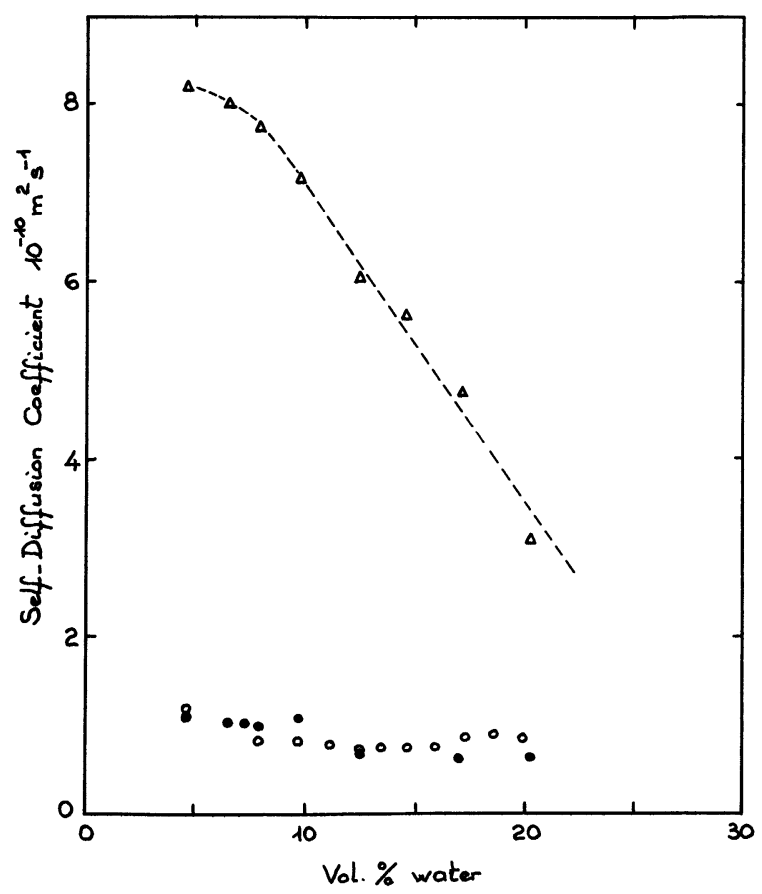

Fig. 5. - Self-diffusion coefficients $D_{\mathrm{S}}(\bullet), D_{\mathrm{Na}}(0)$ and $D_{\mathrm{D}}(\Delta)$ along BB' $^{\prime}$ as a function of the volume fraction of water $\Phi$. The $\Phi$ scale is twice as large on figures 4,5 and 6 as on figure 2. 


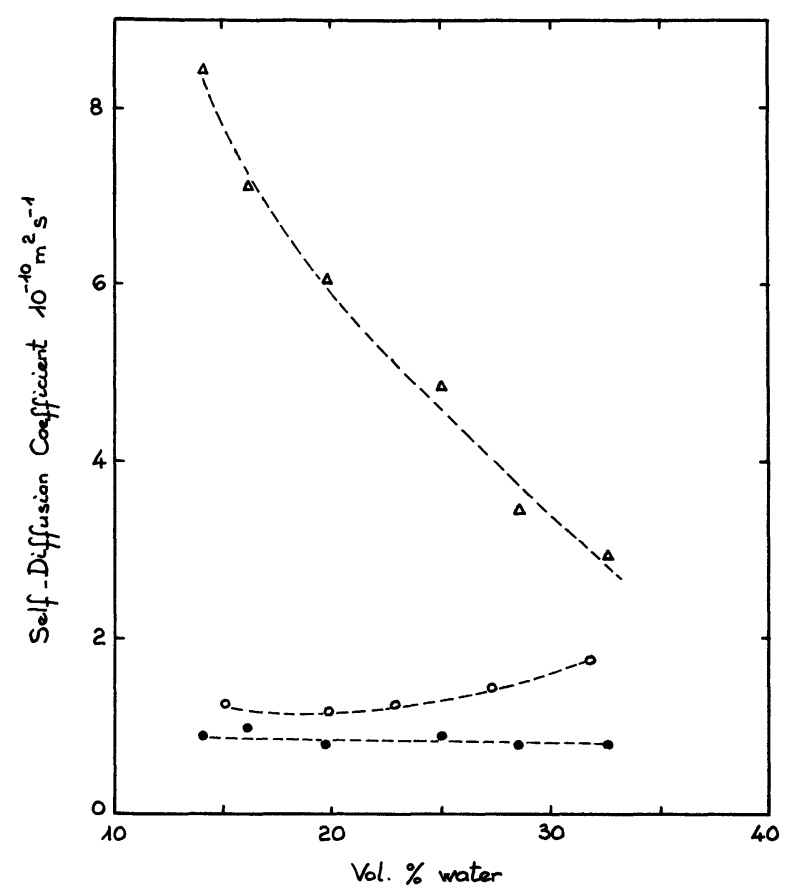

Fig. 6. - Self-diffusion coefficients $D_{\mathrm{S}}(\bullet), D_{\mathrm{Na}}(0)$ and $D_{\mathrm{D}}(\triangle)$ along $\mathrm{CC}^{\prime}$ as a function of the volume fraction of water.

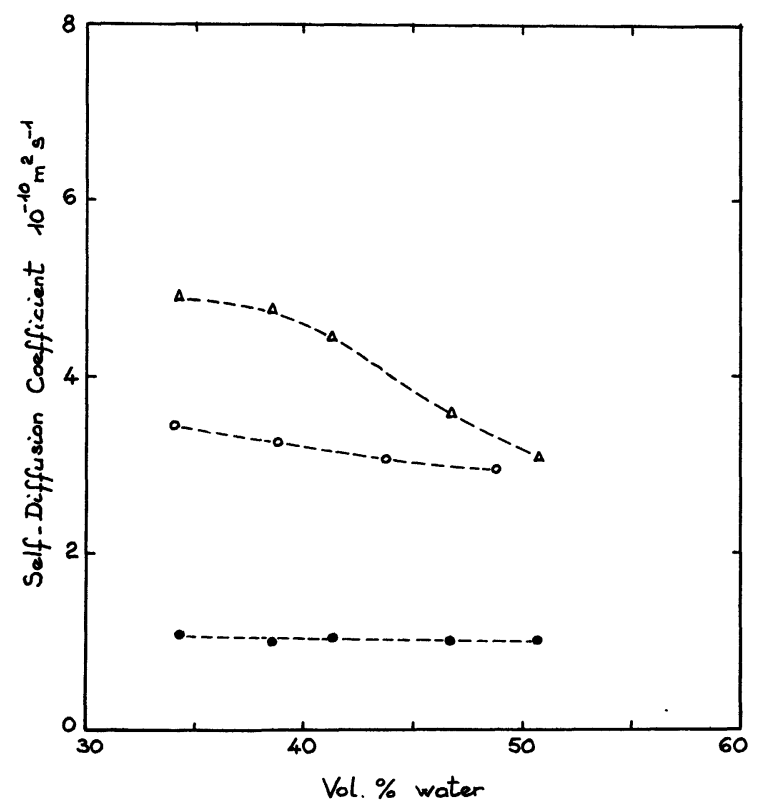

Fig. 7. - Self-diffusion coefficients $D_{\mathrm{S}}(\bullet), D_{\mathrm{Na}}(0)$ and $D_{\mathrm{D}}(\triangle)$ along $\mathrm{DD}^{\prime}$ as a function of the volume fraction of water.

3. Discussion. - The discussion is centred on the structural implications of the data presented. Let us note first that the various measured quantities are all apparent quantities. They depend on the geometrical arrangement in space of the aqueous and the oily part of the microemulsion, as well as on the properties specific to each of these media. The diffusion coefficient of decane for instance depends on the geometry of the oil rich phase as well as on its composition.

At high water volume fraction, the water is expected to be continuous, and the decane in the form of droplets surrounded by the surfactant, the pentanol being partitioned mainly between this interface and the decane. With such structure, the self-diffusion coefficients $D_{\mathrm{S}}$ and $D_{\mathrm{D}}$ should be about equal. This is found toward point F (Fig. 3) and small-angle neutron scattering has shown that, at this point, we are indeed in the presence of a $\mathrm{O} / \mathrm{W}$ microemulsion [15]. The contribution of OBS dissolved in water to $D_{\mathrm{S}}$ is certainly small and would tend to increase this coefficient (at the c.m.c. $D_{\mathrm{S}}$ has the value

$$
\left.6.15 \times 10^{-10} \mathrm{~m}^{2} \cdot \mathrm{s}^{-1}[14]\right) \text {. }
$$

The fact that $D_{\mathrm{S}}$ shows very little variation throughout the composition field investigated is an indication that the previous effect is insignificant.

At low water volume fraction, one expects $\mathrm{W} / \mathrm{O}$ microemulsions which are identical to inverse micellar solutions [16]. With such a structure, $D_{\mathrm{Na}}$ and $D_{\mathrm{Cl}}$ would be equal to $D_{\mathrm{s}}$. This is observed near $\mathrm{A}^{\prime}$.

At intermediate volume fraction of water, all diffusion coefficients are above $D_{\mathrm{S}}$. This is not compatible with structures where one of the phases is totally enclosed in the other. The increase in conductivity between $\Phi \sim 12$ and $20 \%$ water seems to indicate for instance that the water structure opens up. Whether the two phases are completely interconnected cannot be proved. However the linearity of $\lambda$ with $\Phi$ along $\mathrm{AA}^{\prime}$ between 20 and $40 \%$ suggest that this might be true for water. As far as the instantaneous structure is concerned, these microemulsions could be compared to porous media or phase separated glasses [17-19]. Since the diffusion coefficient of decane in decane pentanol mixtures is not known, nor the partition coefficient of pentanol between the decane and the interface, such a model cannot be used to evaluate the apparent diffusion coefficient of the decane and compare these values with the experimental ones. But it is clear that there is no sudden inversion from a W/O to a $\mathrm{O} / \mathrm{W}$ microemulsion along lines like $\mathrm{AA}^{\prime}$.

This transition region, characterized by continuous paths for oil and water, has been called bicontinuous [20]. Its extension can be very approximatively sketched on the basis of diffusion data, in particular $D_{\mathrm{Na}}$. For instance $\mathrm{BB}^{\prime}$ does not enter this region, $\mathrm{DD}^{\prime}$ lies probably in it, $\mathrm{CC}^{\prime}$ is a border case, $\mathrm{AA}^{\prime}$ and $\mathrm{EE}^{\prime}$ cross it.

All the data presented suggest that the limit of the full bicontinuous region does not follow a constant $\Phi$ line. This would be in agreement with calorimetric data on other microemulsions systems [21]. Note also that $D_{\mathrm{D}}$ has different values at the same $\Phi$. This probably indicates a strong influence of the alcohol content in the oily phase.

Let us note also that the value of $D_{\mathrm{w}}$ at the lowest $\Phi$ along $\mathrm{AA}^{\prime}$ may not be quite representative of the water diffusion, since it is known that there is proton exchange between pentanol and water [22]. The water dissolved in the decane could also contribute to $D_{\mathrm{w}}$. 
An evaluation made by the method of Graciaa et al. [23] along the two phases equilibrium line indicates that the water content is about $2.5 \mathrm{wt} . \%$ of the pentanol content. This water being associated with the alcohol has probably a self-diffusion coefficient much lower than it has in pure water (table I). Therefore, it cannot participate significantly in the increase found along $\mathrm{AA}^{\prime}$.

Table I. - Reference self-diffusion coefficients $\left(10^{-10} \mathrm{~m}^{2} \cdot \mathrm{s}^{-1}\right)$.

\begin{tabular}{|c|c|c|c|}
\hline $\begin{array}{c}D_{\mathrm{D}} \\
\text { in pure } \\
\text { decane }\end{array}$ & $\begin{array}{c}D_{\mathrm{w}} \\
\text { in pure } \\
\text { water }\end{array}$ & $\begin{array}{c}D_{\mathrm{Na}} \\
\text { in water } \\
\text { containing } \\
0.3 \text { wt. } \% \mathrm{NaCl} \\
{[14]}\end{array}$ & $\begin{array}{c}D_{\mathrm{s}} \\
\text { at the c.m.c. } \\
\left(1.28 \times 10^{-2} \mathrm{~mol} . \mathrm{kg}^{-1}\right) \\
{[14]}\end{array}$ \\
\hline 13.1 & 22.5 & 12.8 & 6.15 \\
\hline
\end{tabular}

4. Conclusions. - Self-diffusion and conductivity measurements along various lines of a pseudo-ternary diagram oil-water-surfactant-alcohol show that the solutions in the homogeneous region (microemulsion) can exist under very different structures. For the particular system studied a bicontinuous structure seems to exist at water volume fraction between $\sim 16$ and $40 \%$. This type of two phases structure separated by an extended interfacial structure has been suggested by Adamson [24] and Scriven [20]. In the whole domain of investigation, there is no inversion of the structure contrary to what has been proposed for others systems [7]. The path from $\mathrm{W} / \mathrm{O}$ to $\mathrm{O} / \mathrm{W}$ microemulsions seems to cross necessarily an extended bicontinuous zone. Its boundaries are strongly related to the water volume fraction of the solutions but depend however on other factors. Their determination is certainly a prerequisite for further physicochemical studies of these systems.

There are also suggestions that structures different from direct, inverted or bicontinuous exist in this homogeneous zone. Investigation along this lines are in progress.

\section{References}

[1] Rosoff, M., Prog. Surf. Membr. Sci. 12 (1978) 405.

[2] Wennerström, H., Lindman, B., Phys. Rep. 52 (1979).

[3] Graciaa, A., Lachaise, J., Chabrat, P., Letamendia, L. Rouch, J., Vaucamps, C., J. Physique Lett. 39 (1978) L-235.

[4] Cazabat, A. M., Langevin, D., Pouchelon, A., J. Colloid Interface Sci. 73 (1980) 1.

[5] Herrmann, C. U., Würz, V., Kahlweit, M., Ber. Bunsenges. Phys. Chem. 82 (1978) 560.

[6] Cabos, C., Delord, P., J. Physique 39 (1978) 432.

[7] Lagües, M., Ober, R., TAuPIN, C., J. Physique Lett. 39 (1978) L-487.

[8] Shah, D. O., Hamlin, R. M., Science 171 (1971) 483.

[9] Friberg, S., Burasczenska, I., Prog. Colloid Polym. Sci. 63 (1978) 1.

[10] GraciaA, A., Thesis, Pau (1978).

[11] Kathopoulis, T. M., Thesis, Montpellier (1979).

[12] Lindman, B., Kamenka, N., Kathopoulis, T. M., Brun, B., Nilson, P. G., J. Phys. Chem., accepted.

[13] Handbook of Physics and Chemistry, 56th ed. (C.R.C. Press; Cleveland) 1975.
[14] Kamenka, N., Chorro, M., Fabre, H., Lindman, B., Rouvière, J., Cabos, C., Colloid Polym. Sci. 257 (1979) 757.

[15] Delord, P., unpublished results.

[16] SJöвlom, E. and Friberg, S., J. Colloid Interface Sci. 67 (1978) 16.

[17] Nordberg, M. E., J. Am. Ceram. Soc. 27 (1944) 299.

[18] Charles, R. J., J. Am. Ceram. Soc. 47 (1964) 559.

[19] Cahn, J. W. and Charles, R. J., Phys. Chem. Glasses 6 (1965) 181.

[20] SCRIVEN, L. E., in Micellization, Solubilization and Microemulsions, Mitall, K. L. ed. (Plenum Press, New York and London) 1976, vol. 2.

[21] ViallaRd, A., D.G.R.S.T., Annual Report, Contract 78.7. 2198 (1979).

[22] Emsley, J. W., Feeney, S., Sutcliffe, L. H., High-Resolution Nuclear Magnetic Resonance Spectroscopy (Pergamon Press, Oxford) 1965.

[23] GraciaA, A., Lachaise, J., Martinez, A., Bourrel, M., Снамвu, C., C.R. Hebd. Séan. Acad. Sci., Paris B 282 (1976) 547.

[24] Adamson, A. W., J. Colloid Interface Sci. 29 (1969) 261. 